Tropical Journal of Pharmaceutical Research November 2017; 16 (11): 2761-2772

ISSN: $1596-5996$ (print); 1596-9827 (electronic)

(c) Pharmacotherapy Group, Faculty of Pharmacy, University of Benin, Benin City, 300001 Nigeria.

All rights reserved.

Available online at http://www.tjpr.org

Original Research Article

http://dx.doi.org/10.4314/tjpr.v16i11.26

\title{
Efficacy of EGFR-TKI therapy in patients with brain metastases from non-small-cell lung cancer: A meta- analysis
}

\author{
Wei Zhang ${ }^{1,2 *}$, Lijuan $\mathrm{Hu}^{3}$, Caihong Huang ${ }^{4}$, Jun Ying ${ }^{1}$, Naiqing Zhao ${ }^{1 *}$ \\ ${ }^{1}$ Department of Biostatistics, School of Public Health, ${ }^{2}$ Fudan University Library, Shanghai, ${ }^{3}$ Department of Pulmonary \\ Medicine, Research Institute of Respiratory Disease, Zhongshan Hospital, Shanghai, ${ }^{4}$ Xuhui Central Hospital, Shanghai, China \\ ${ }^{*}$ For correspondence: Email: nqzhao@fudan.edu.cn; Tel: +86-21-54237485
}

Sent for review: 23 September 2017

Revised accepted: 31 October 2017

\begin{abstract}
Purpose: This meta-analysis aimed to systematically evaluate the efficacy of tyrosine kinase inhibitors of epidermal growth factor receptor (EGFR-TKIs) for patients with brain metastases (BM) from nonsmall-cell lung cancer (NSCLC), and to compare this treatment modality to chemotherapy or radiotherapy.

Methods: PubMed, EMBASE (OvidSP), the Cochrane Central Register of Controlled Trials (CENTRAL), Web of Science and ASCO Annual Meeting Abstracts were searched. Controlled clinical studies that compared the efficacy of EGFR-TKIs with chemotherapy or radiotherapy for NSCLC patients with BM were included in the analysis. Efficacy indicators included overall survival (OS), local progression-free survival (LPFS) and objective response rate (ORR).

Results: The final sample consisted of 24,637 NSCLC patients with BM from 11 clinical studies. In primary efficacy analysis, it was found that EGFR-TKIs were significantly superior to chemotherapy or radiotherapy in terms of ORR (odds ratio $(O R)=2.10, p=0.035$ ), OS (hazard ratio $(H R)=0.78, p=$ $0.011)$ and LPFS $(H R=0.60, p<0.001)$.

Conclusion: Among the patients with BM from NSCLC, EGFR-TKIs exhibit a therapeutic advantage over chemotherapy or radiotherapy, which is reflected in the elevation of ORR and improvement in OS and LPFS.
\end{abstract}

Keywords: Brain metastasis, Non-small-cell lung cancer (NSCLC), Protein kinase Inhibitors, Epidermal growth factor, Meta-analysis

Tropical Journal of Pharmaceutical Research is indexed by Science Citation Index (SciSearch), Scopus, International Pharmaceutical Abstract, Chemical Abstracts, Embase, Index Copernicus, EBSCO, African Index Medicus, JournalSeek, Journal Citation Reports/Science Edition, Directory of Open Access Journals (DOAJ), African Journal Online, Bioline International, Open-J-Gate and Pharmacy Abstracts

\section{INTRODUCTION}

Lung cancer is the most common cancer and is the major cause of cancer-related deaths, accounting for $13.0 \%$ of new cancer cases and $19.4 \%$ of cancer-related deaths in men and women according to the 2012 statistics [1]. About $85 \%$ of the lung cancer cases are classified as NSCLC [2], which has a relatively high risk of $\mathrm{BM}$, ranging from 20 to $40 \%$ [3,4]. The prognosis of NSCLC patients with BM is very unsatisfactory, with median OS time being $<3$ months if untreated [5].

The therapies for NSCLC patients with BM include surgery, stereotactic radiosurgery (SRS), chemotherapy, whole brain radiation therapy (WBRT), EGFR-TKIs or any combinations thereof. However, chemotherapy is not a routine treatment because of the inability of many systemically active chemotherapeutic drugs to cross the blood-brain barrier (BBB). Surgery and 
SRS are not ideal options for NSCLC patients with BM considering the poor outcome. WBRT has been regarded as the standard treatment plan for multiple BM; it can stabilize or shrink tumors in at least half of the patients, but many patients experience tumor recurrence either at the original sites or at new sites [6].

As micro-molecularly-targeted drugs, EGFRTKIs, such as gefitinib or erlotinib, can penetrate the BBB in a certain proportion $[7,8]$. This is an important characteristic to consider when the treatment options of patients with BM from NSCLC are evaluated. In addition, EGFR-TKIs are believed to possess the ability to reinforce radioactive sensitivity through multiple means $[9,10]$.

Many studies have shown the responses of NSCLC patients with BM to EGFR-TKIs [11-14], but most of the studies involved small sample sizes, contained only case reports, or were single-arm. Moreover, negative conclusions were reached based on the findings from some studies. For example, OS, PFS and toxicity in the WBRT + SRS + erlotinib group were completely less satisfactory when compared to those of the WBRT + SRS group in a phase III clinical trial. Three meta-analyses on the benefit of EGFRTKIs among patients with BM from NSCLC have also been published, but only one included 16 single-arm studies [15] and the other two $[16,17]$ respectively evaluated the efficacy and safety of TKIs and radiotherapy in relatively few participants.

In 2015, Lin [18] found extended period of survival in NSCLC patients with BM who were receiving gefitinib or gamma knife radiosurgery by analyzing medical records of 23,874 target patients based on the National Health Insurance Research Database of Taiwan from 2004 to 2010. Results from such large sample size studies provide more dependable data. Therefore, in the present study, we performed this meta-analysis to systematically examine the efficacy of EGFR-TKIs for NSCLC patients with $\mathrm{BM}$, and the outcome of this treatment modality was compared with those of chemotherapy and radiotherapy. This pooled evaluation, based on controlled studies can assist doctors to make better clinical decisions for the treatment of NSCLC patients with BM.

\section{METHODS}

\section{Data sources}

Our meta-analysis was based on the preferred reporting items for systematic reviews and meta- analyses (PRISMA) Statement, in which PubMed, EMBASE (OvidSP), the Cochrane Central Register of Controlled Trials (CENTRAL, last issue), Web of Science and ASCO (The American Society of Clinical Oncology) annual meeting abstracts which were painstakingly searched for the presence of relevant papers that were published from January 2000 until December 2016. The keywords were as follows: non-small cell lung cancer OR non-small cell lung carcinoma OR NSCLC OR large cell lung cancer OR lung adenocarcinoma OR lung squamous cell carcinoma OR lung squamous carcinoma; epidermal growth factor receptor OR EGFR OR erbB-1 OR erlotinib OR gefitinib OR Tarceva OR Iressa OR ZD1839 OR icotinib OR afatinib OR Gilotrif; and brain metastasis OR central nervous system metastasis OR CNS metastasis OR cerebral metastasis. The subject heading search was also performed in specific databases. Moreover, other conference papers and the reference lists of selected studies were searched for manually. The search for publications was not restricted to type of publication and language in which they were published.

\section{Study selection}

Two of the authors (ZW and HLJ) reviewed the titles and abstracts of all papers identified from electronic sources and those from manual retrieval, respectively. Only studies that met the following eligibility criteria were included for the purpose of quantitative synthesis: (a) controlled clinical studies (even retrospective clinical designs in consideration of the small number of eligible publications) in which the experimental group received EGFR-TKls alone or a combination of EGFR-TKIs with chemotherapy or radiotherapy and in which the control group received only chemotherapy, radiotherapy or a combination of chemotherapy and radiotherapy; (b) the patients in the studies or in the subgroup analyzed and confirmed to have NSCLC with brain metastasis; (c) original papers that contained adequate data to estimate the indicators of efficacy with a $95 \%$ confidence interval $(95 \% \mathrm{Cl})$. Repeated publication and nonoriginal literature (e.g., comment, letter, review, etc.) were excluded. If no agreement could be reached after a discussion between the two reviewers in terms of study selection, a third investigator $(\mathrm{HCH})$ made the final decision.

\section{Efficacy indicators}

The ORR was defined as the percentage of complete response and partial response among the evaluated patients. OS referred to the time 
from randomization to death regardless of the cause of death. LPFS was thought as the length of time from randomization to central nervous system, neurological or intracranial progression or death. In this meta-analysis, the odds ratio (OR) for the ORR and the hazard ratios (HRs) for OS and LPFS were primary indicators for the assessment of the efficacy of EGFR-TKIs for NSCLC patients with BM.

\section{Data extraction and quality assessment}

In the meta-analysis, the following information was collected independently by two authors (ZW and HLJ) from each study: first author, publication year, country of study, study design, treatments in the different groups, number of patients, endpoint types, patient characteristics (age, gender, stage, response status, EGFR mutation status) and outcome measures (response rate, median OS and LPFS, HRs for OS and LPFS and their $95 \%$ Cls). Results that were obtained by multivariate analysis were preferred. If the HRs for OS or LPFS were not provided in the papers, log-transformed HRs and variance were estimated from Kaplan-Meier curves with the Engauge graphic software package [19]. Moreover, the risks of bias of the included studies were evaluated independently by two authors (ZW and HLJ) on the basis of The Cochrane Handbook for Systematic Reviews (version 5.1.0). $\mathrm{HCH}$ was still the final decisionmaker when no consensus could be reached between the other two reviewers.

This research was approved by the Ethical Committee of Department of Biostatistics, School of Public Health, Fudan University, Shanghai, China according to the Declaration of Helsinki promulgated in 1964 as amended in 1996 [20].

\section{Statistical analysis}

The analysis was based on the intention-to-treat (ITT) principle. Potential heterogeneity was first detected among the studies using Cochran's Qstatistic and $\mathrm{I}^{2}$ score [21], which is thought as statistically significant if the p-value for heterogeneity is less than 0.10 or if $\mathrm{I}^{2}$ is greater than $50 \%$. If heterogeneity was found, the random-effects model [22] was applied to pool all effect measures including odds ratio for the objective response rate and HRs for OS and LPFS; otherwise, the fixed-effects model (inverse variance method) [23] was used. To assess the presence of possible publication bias, Egger's regression asymmetry test with a funnel plot was performed [24]. Its significant level was 0.10 . The sensitivity analysis was performed to examine the influence of the study design, study quality and treatment plan on the evaluation of the study's efficacy.

The statistical software package used was STATA 11.2 (Stata Corporation, College Station, TX, USA). All $p$-values were two-sided. For the examination of the pooled effect indicators, $p<$ 0.05 was considered as statistical significance.

\section{RESULTS}

\section{Characteristics of studies}

From the 266 studies that were screened, 216 articles were excluded because of apparent nonconformity with the eligibility criteria, and 50 fulltext papers were accessed to further evaluate their eligibility. Next, 15 studies were enrolled in the qualitative synthesis, and 11 studies (see 18, $25-34$, Table 1 ) that met all criteria were finally selected for the quantitative synthesis. A flowchart of the selection process is presented in Figure 1. The 11 eligible studies included 2 phase III trials, 3 phase II trials, 1 undefined phase trial and 5 retrospective clinical studies. The final sample consisted of 24,637 patients with BM from NSCLC, which included 3,773 in the EGFR-TKIs arm and 20,864 in the control group. Five of the 11 studies were from the Chinese mainland, 2 from Taiwan, 1 from Germany, 1 from the United Kingdom, 1 from the United States and 1 from Switzerland. All subjects in study 1 (one) were EGFR-mutant, and 2 studies provided the subgroup analysis for EGFR-mutant and EGFR wild-type patients, but the mutation status for the rest of the patients could not be verified or analyzed. Of the 11 eligible studies, 3 featured EGFR-TKI combination therapy compared with combined radiotherapy or chemotherapy, 5 featured EGFRTKI combination therapy compared with radiotherapy alone, and 3 featured EGFR-TKI alone compared with chemotherapy or radiotherapy alone. All studies included were peer-reviewed. The characteristics of the included studies are summarized in Table 1.

\section{Primary efficacy analysis}

Among the 11 included studies, 6 reported objective response rates (numbers 26-28; 20-32; Table 1), and a statistically significant heterogeneity was detected across the studies $\left(\mathrm{I}^{2}\right.$ $=91.1 \%, p<0.001)$. The pooled OR for the ORR obtained by a random effects model was 2.10 (95\% Cl: $1.05-4.20, p=0.035$, Figure 2). From these data, EGFR-TKIs were significantly better than chemotherapy or radiotherapy. 
Table 1: Characteristics of the studies included in the meta-analysis

\begin{tabular}{|c|c|c|c|c|c|c|c|c|c|c|}
\hline Author & Year & Country & Type of study & EGFR mutation (+) & Treatment & $\mathbf{N}$ & ORR (\%) & OS (months) & LPFS (months) & Quality \\
\hline \multirow[t]{2}{*}{ Lin, $C[18]$} & 2015 & TW & retrospective & Portion of patients & GFT + WBRT & 3379 & NA & 6.4 & NA & B \\
\hline & & & & & WBRT & 20241 & NA & 12.1 & NA & \\
\hline \multirow[t]{2}{*}{ Sperduto, PW [25] } & 2013 & USA & phase III & Unselected & ETN+WBRT + SRS & 41 & NA & 6.1 & 4.8 & $B$ \\
\hline & & & & & WBRT + SRS & 44 & NA & 13.4 & 8.1 & \\
\hline \multirow[t]{2}{*}{ Schuler, M[26] } & 2016 & GER & phase III & All patients & Afatinib & 48 & 75.0 & 22.4 & 8.2 & A \\
\hline & & & & & Pemetrexed/ Cisplatin & 33 & 27.8 & 25.0 & 5.4 & \\
\hline \multirow[t]{2}{*}{ Cai, Y[27] } & 2013 & PRC & retrospective & Portion of patients & (GFT or ETN)+WBRT & 65 & 76.9 & 10.6 & 6 & $B$ \\
\hline & & & & & WBRT & 92 & 70.7 & 7.7 & 3.4 & \\
\hline \multirow[t]{2}{*}{$F u, H[28]$} & 2012 & PRC & retrospective & Unselected & GFT $+($ WBRT or SRS) & 38 & 31.6 & NA & NA & C \\
\hline & & & & & WBRT or SRS & 123 & 15.4 & NA & NA & \\
\hline \multirow[t]{2}{*}{ Lee, SM [29] } & 2014 & UK & phase II & Portion of patients & ETN+WBRT & 40 & NA & 3.4 & 1.6 & $B$ \\
\hline & & & & & Placebo +WBRT & 40 & NA & 2.9 & 1.6 & \\
\hline \multirow[t]{2}{*}{ Wang, F[30] } & 2014 & PRC & undefined phase & Portion of patients & $\mathrm{GFT}+\mathrm{RT}$ & 37 & 54.1 & 13.3 & NA & B \\
\hline & & & & & $\mathrm{VMP}+\mathrm{RT}$ & 36 & 47.1 & 12.7 & NA & \\
\hline
\end{tabular}

Table 1(b): Characteristics of the studies included in the meta-analysis

\begin{tabular}{|c|c|c|c|c|c|c|c|c|c|c|}
\hline Author & Year & Country & Type of study & EGFR mutation (+) & Treatment & $\mathbf{N}$ & ORR (\%) & OS (months) & LPFS (months) & Quality \\
\hline \multirow[t]{2}{*}{ Zhuang, $H Q$ [31] } & 2013 & PRC & phase II & Portion of patients & ETN+WBRT & 23 & 95.7 & 10.7 & 6.8 & \\
\hline & & & & & WBRT & 31 & 54.8 & 8.9 & 5.2 & \\
\hline \multirow[t]{2}{*}{ Hsiao, $\mathrm{SH}[32]$} & 2013 & TW & retrospective & Portion of patients & EGFR TKIs & 11 & 55 & 9.8 & NA & $\mathrm{B}$ \\
\hline & & & & & RT & 70 & 76 & 10.6 & NA & \\
\hline Fan, Y[33] & & & & & Chemotherapy & 111 & NA & 9 & NA & \\
\hline \multirow[t]{2}{*}{ Pesce, GA[34] } & 2011 & $\mathrm{CH}$ & phase II & Unselected & $\mathrm{GFT}+\mathrm{RT}$ & 16 & NA & 6.3 & 4.8 & B \\
\hline & & & & & $\mathrm{TMZ}+\mathrm{RT}$ & 43 & NA & 4.9 & 8.0 & \\
\hline
\end{tabular}

Key: NA: not available WBRT: whole brain radiotherapy SRS: stereotactic radiosurgery ETN: Erlotinib GFT: Gefitinib TMZ: Temozolomide RT: Radiotherapy 


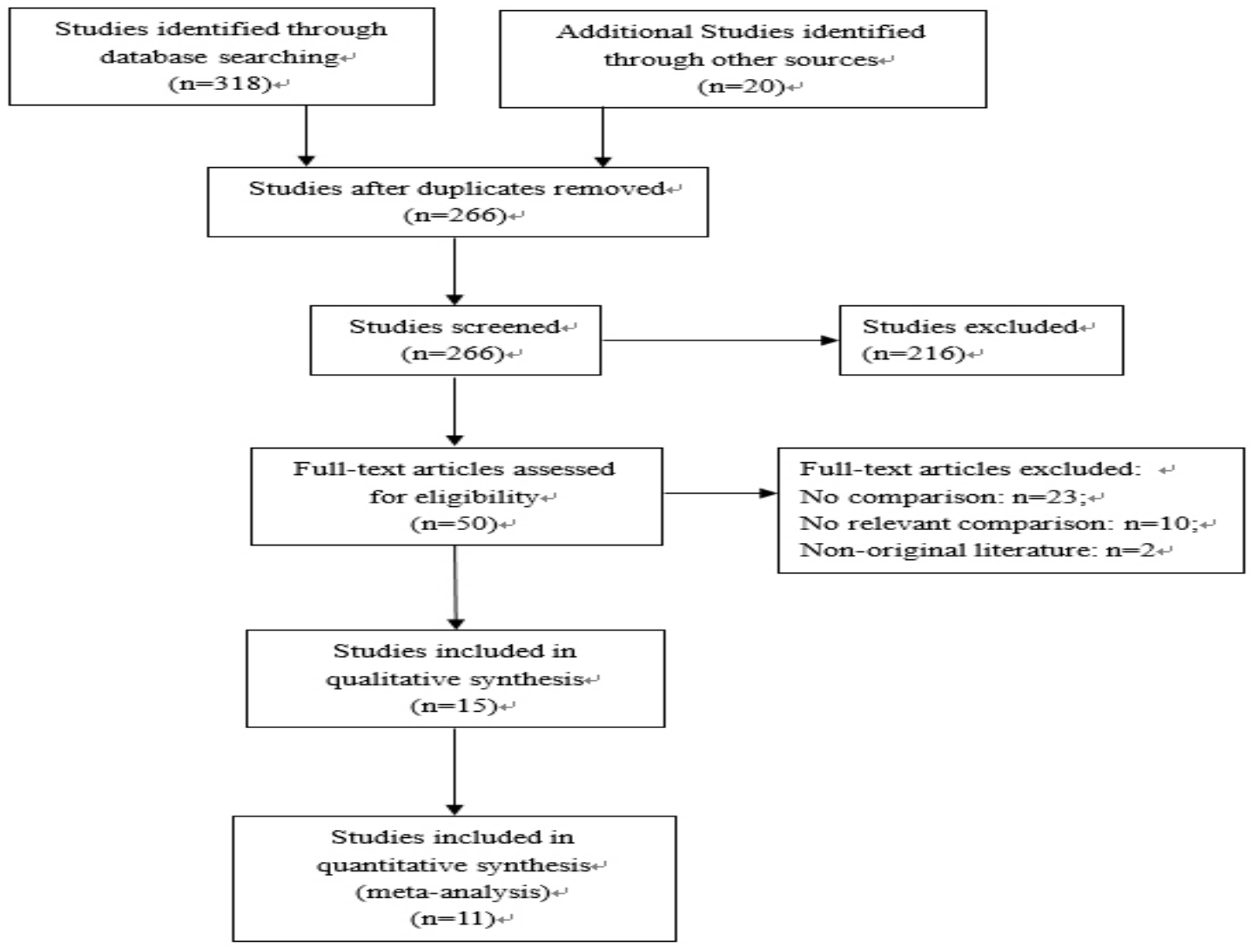

Figure 1: PRISMA flow diagram of the identification process

Study

OR $(95 \% \mathrm{Cl}) \quad$ Weight

ID

OR $(95 \% \mathrm{Cl})$

Weight

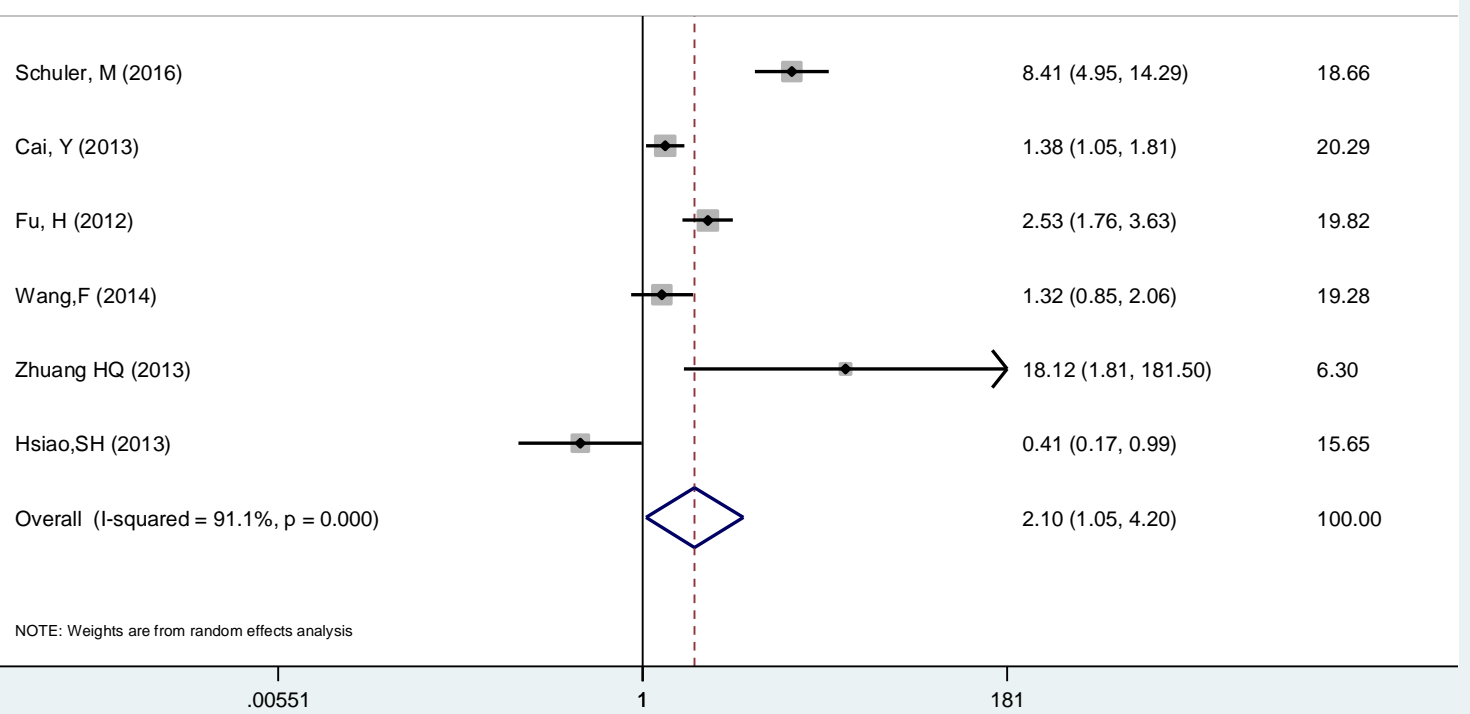

Figure 2: Forest plot of odds ratios for the objective response rate according to primary efficacy analysis 
Data on the OS were available in 10 studies [18,26-34], and the pooled HR for the OS was 0.78 (95\% Cl: $0.65-0.94, p=0.011$, Figure 3), which presented a significant difference between EGFR-TKIs and chemotherapy or radiotherapy. A random effects model was also used on account of significant heterogeneity $\left(\mathrm{I}^{2}=70.8 \%\right.$, $p<0.001$ ).

The HRs for the LPFS with a $95 \% \mathrm{Cl}$ were provided in 4 studies $[26,27,29,31]$, and the pooled HR between EGFR-TKIs and chemotherapy or radiotherapy was regarded as significantly different $(\mathrm{HR}=0.60,95 \% \mathrm{Cl}: 0.47-$ $0.78, p<0.001$, Figure 4) using a fixed effects model $\left(I^{2}=44.8 \%, p=0.143\right)$. These results clearly favored EGFR-TKIs.

\section{Sensitivity analysis}

One sensitivity analysis was performed by the inclusion of only 6 randomized controlled trials (RCTs) [25,26,29-31,34]. The LPFS in the EGFR-TKIs treatment group was significantly better than that in the control group (HR: 0.63, 95 $\%$ Cl: $0.44-0.89, p=0.009$, Figure 5), but negative results were found in terms of the ORR and the OS (OR for ORR: 4.81, $95 \% \mathrm{Cl}: 0.98-$ 23.69, $p=0.054$; HR for OS: 0.97, $95 \% \mathrm{Cl}: 0.77$ $-1.21, p=0.768$, Figure 5).
In another sensitivity analysis, only 8 studies that featured the treatment group that received radiotherapy combined with EGFR-TKIs were included [18,25,27-31,34]. All the efficacy indicators showed a significant improvement among patients in the EGFR-TKI plus concurrent radiotherapy group when compared with patients who received radiotherapy alone, chemotherapy alone or a combination of radiotherapy and chemotherapy (OR for ORR: 1.82, $95 \%$ Cl: 1.14 $-2.92, p=0.012$; HR for OS: 0.78, $95 \% \mathrm{Cl}: 0.64$ $-0.97, p=0.024$; HR for LPFS: 0.59 , $95 \% \mathrm{Cl}$ : $0.37-0.97, p=0.036$, Figure 6).

\section{Publication bias}

The result of Egger's asymmetry test did not show any evidence of publication bias $(p=0.683$ for ORR, $p=0.558$ for OS, $p=0.427$ for LPFS, Figure 7).

\section{DISCUSSION}

The meta-analysis carried out in the present study included 24,637 NSCLC patients with BM from 6 randomized controlled trials and 5 retrospective clinical studies. The vast majority of the patients came from East Asia, including the Chinese mainland and Taiwan. This metaanalysis was aimed at assessing the value of EGFR-TKIs therapy in NSCLC patients with BMs.

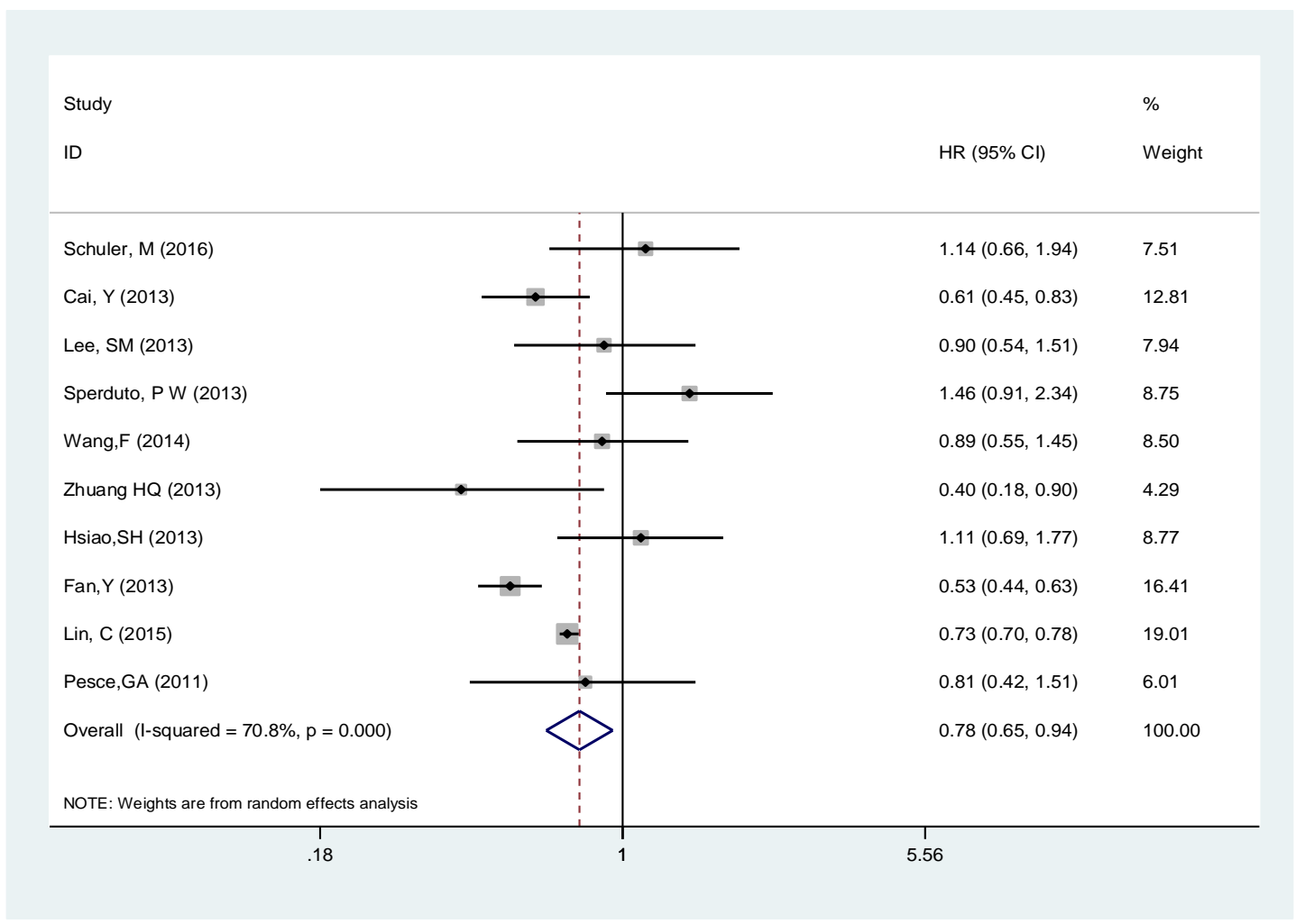

Figure 3: Forest Plot of the hazard ratio for the overall survival according to primary efficacy analysis 


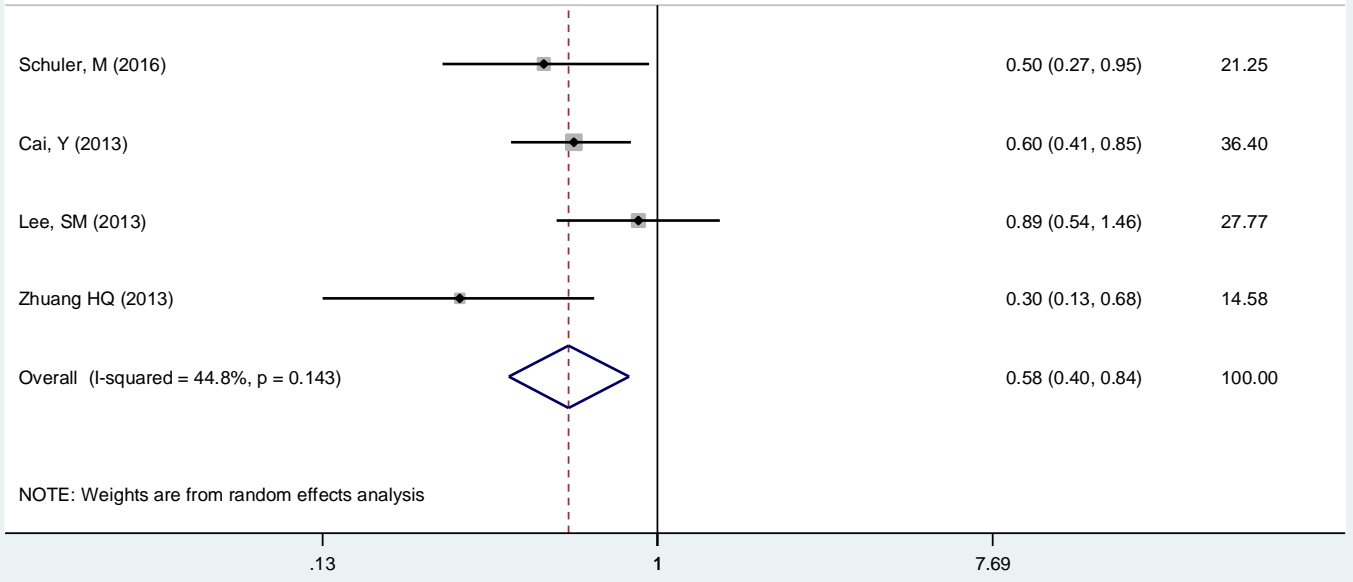

Figure 4: Forest Plot of the hazard ratio for the LPFS according to primary efficacy analysis

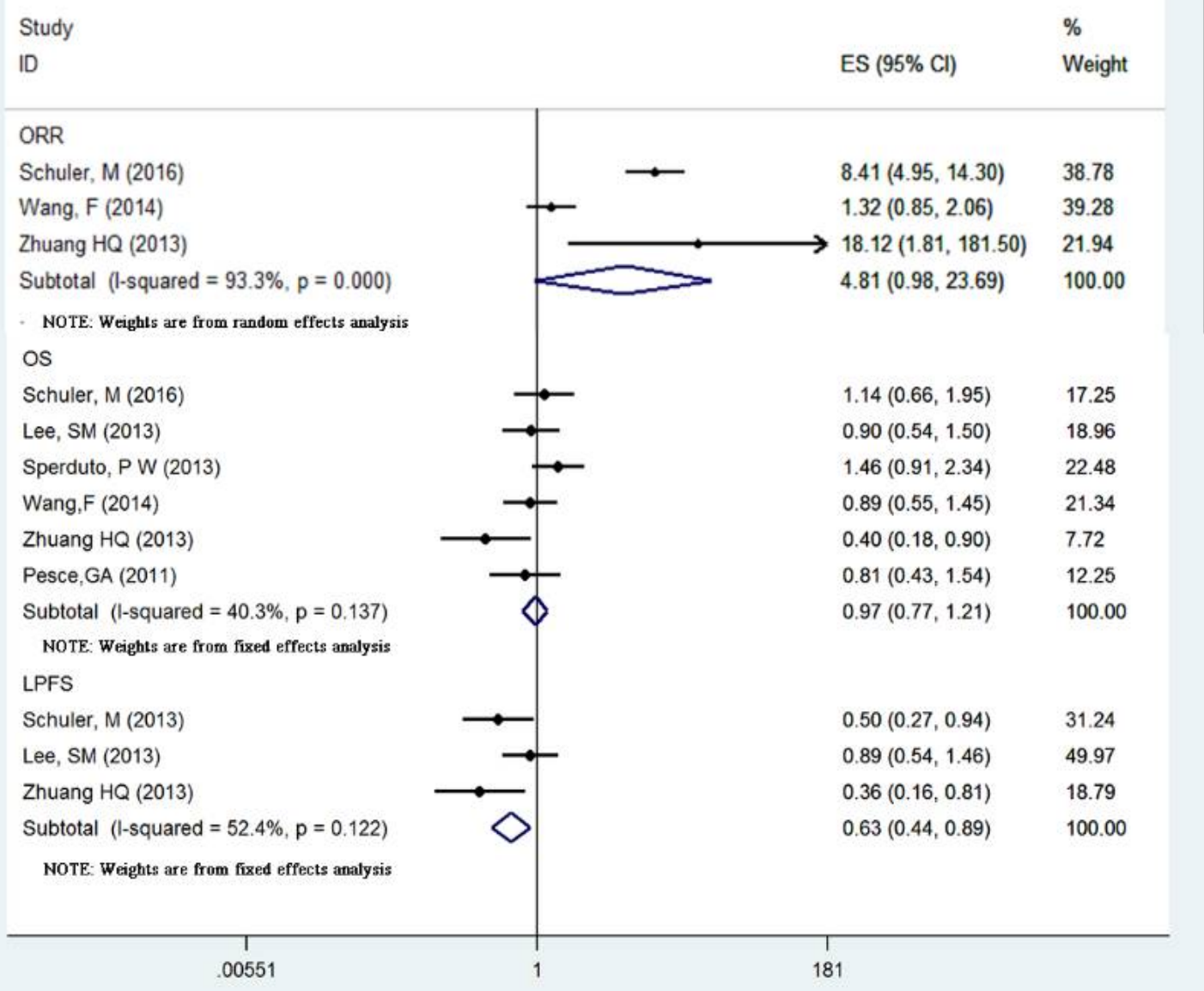

Figure 5: Forest Plot of the efficacy indicators in the sensitivity analysis that only included randomized controlled trials. Pooled result of the ORR was from a random effects analysis, while the OS and the PFS were from a fixed effects analysis 


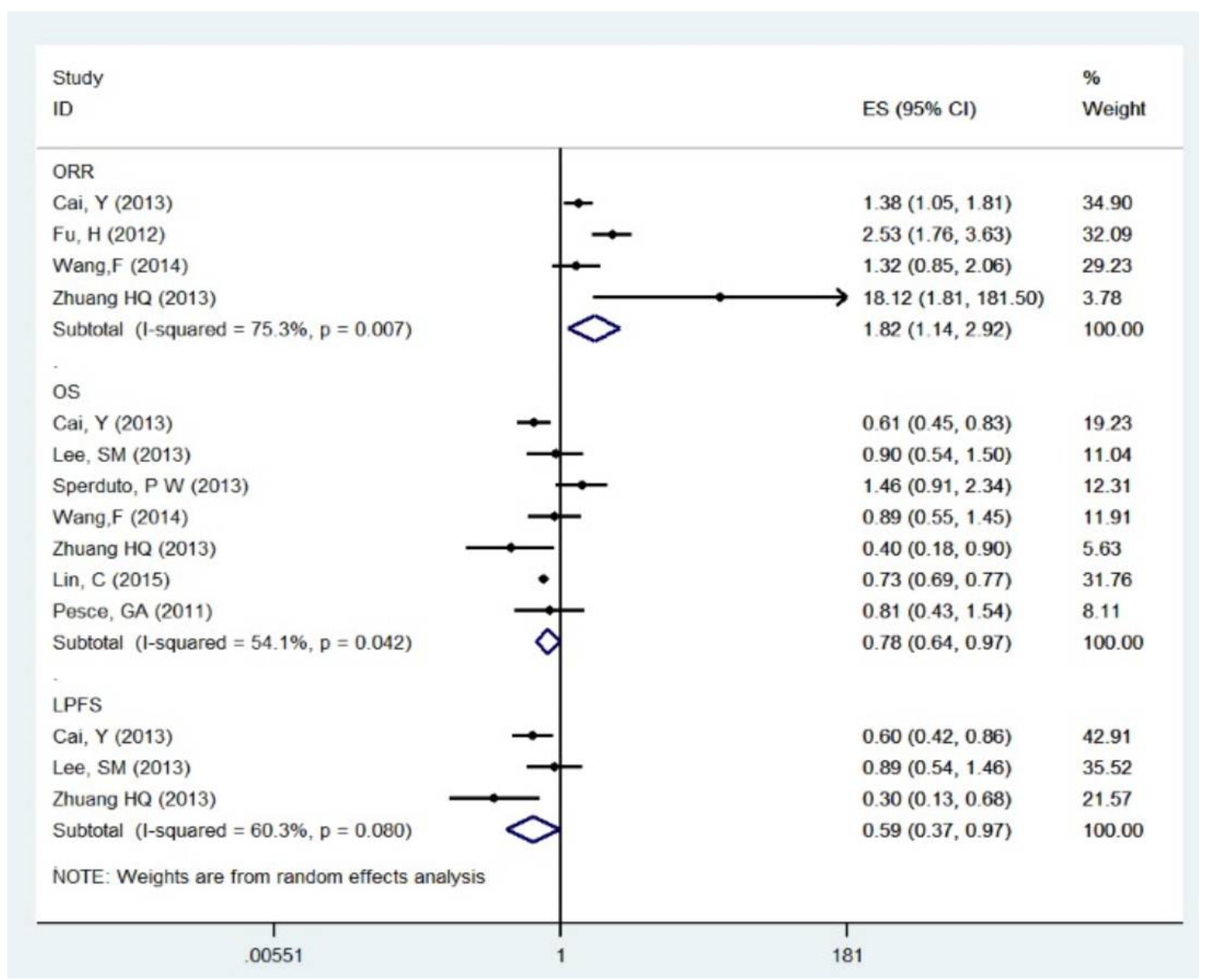

Figure 6: Forest Plot of efficacy indicators in the sensitivity analysis that only included the studies with combined radiotherapy in the EGFR-TKI treatment group. Pooled results of the ORR and the OS were from a random effects analysis, while the PFS was from a fixed effects analysis.

The results indicated that EGFR-TKls were significantly superior to chemotherapy or radiotherapy in terms of ORR (OR $=2.10, p=$ $0.035)$, OS (HR $=0.78, p=0.011)$ and LPFS (HR $=0.60, p<0.001)$. The data suggested that EGFR-TKIs therapy for advanced NSCLC patients with BM not only could improve the short-term quality of life, but also could prolong the overall lifespan.

Systemic chemotherapy for central nervous system (CNS) metastases has only played a limited role in the treatment of patients with BM from NSCLC because of the existence of the blood-brain barrier (BBB). However, as a micromolecule and highly permeable compound, an EGFR-TKI can pass through the BBB in a certain proportion and target intracranial lesions. A pharmacokinetic study indicated that the penetration rates of erlotinib and gefitinib in the cerebrospinal fluid (CSF) were $2.77 \pm 0.45 \%$ and $1.13 \pm 0.36 \%$, respectively [35]. In clinical practice, EGFR-TKls were thought to be an important treatment option for these patients. The present meta-analysis strengthened the evaluation of the therapeutic efficacy of EGFR-
TKIs in a target population by pooling all the existing controlled studies, in which three primary measures favored EGFR-TKI therapy.

WBRT is considered as the standard treatment plan for multiple brain metastases because radiation not only kills the tumor cells, but also damages endothelial cells of the BBB and thus increases its permeability. This characteristic can increase the concentration of EGFR-TKIs in the brain without a dose escalation and it also allows for the combination of EGFR-TKI therapy and WBRT [36]. In addition, EGFR-TKIs are able to sensitize tumor cells to radiation and improve local control rates. Thus, the combination of EGFR-TKIs with concurrent radiotherapy seems to have a strong theoretical basis for the production of a synergistic action that enhances the therapeutic efficacy and reduces the side effects of each therapy. In a phase II trial of erlotinib with concurrent WBRT for patients with BM from NSCLC that was published in Journal of Clinical Oncology in 2013 [37], the ORR was 86 $\%$, and the median OS was 11.8 months (95\% Cl: $7.4-19.1$ months). 

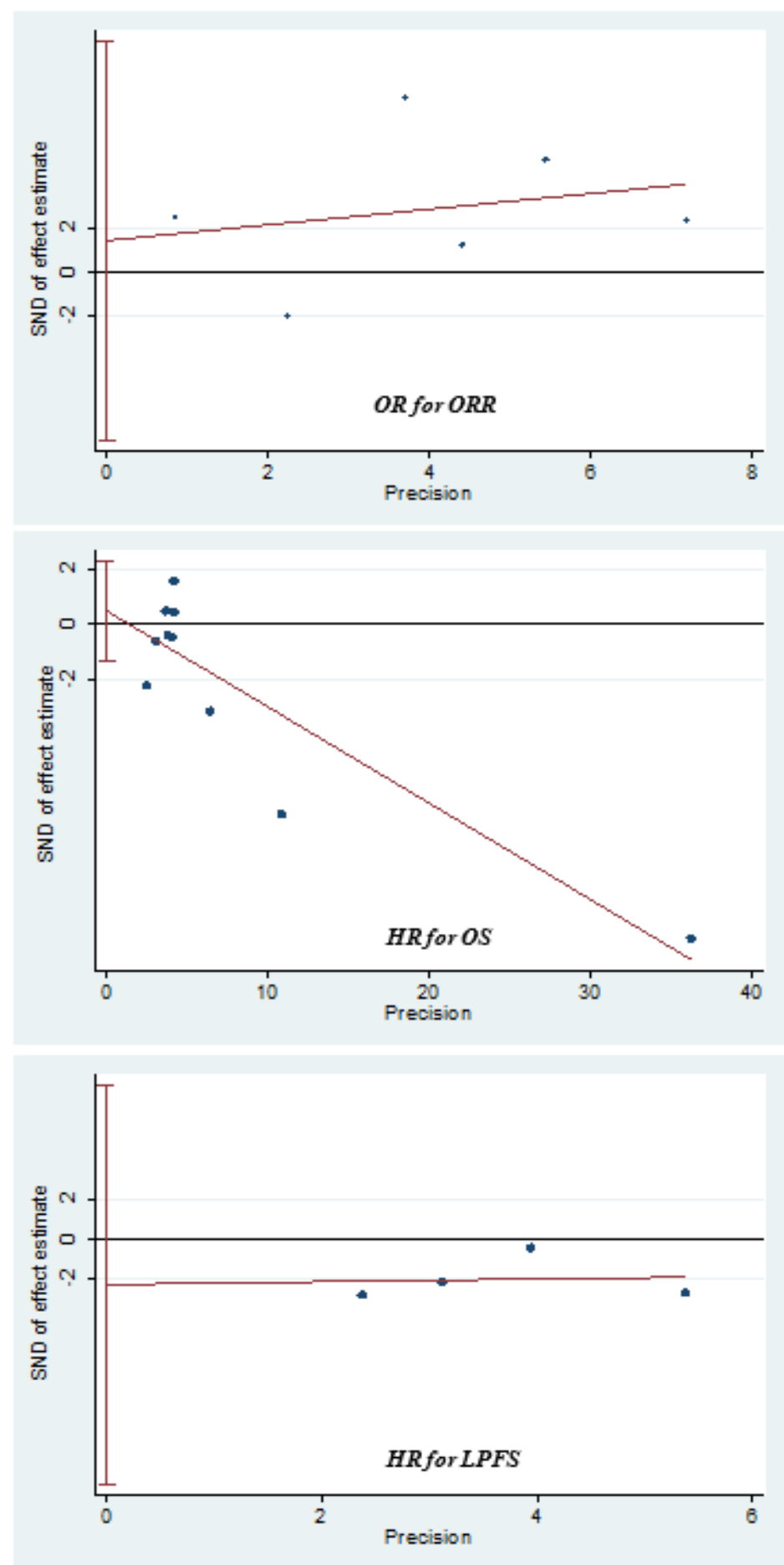

Figure 7: Egger's publication bias plot

Meanwhile, no increase in neurotoxicity, or any grade $>/=4$ toxicity, was detected. A metaanalysis [16] also suggested, by evaluating the therapeutic effects among 980 NSCLC patients with BM, that EGFR-TKIs combined with radiotherapy produced superior efficacy and safety. The efficacy of combination therapy was similarly confirmed by a sensitivity analysis in this study, which was performed by the inclusion of
24,289 participants from the studies with groups that received a combination of radiotherapy and EGFR-TKIs. In this analysis, the ORR, OS and LPFS of patients who received concurrent EGFR-TKIs and radiotherapy were significantly superior to the same indicators of patients who received radiotherapy alone, chemotherapy alone or a combination of chemotherapy and radiotherapy (OR for ORR: 1.82, $p=0.012$; HR 
for OS: $0.78, p=0.024$; HR for LPFS: $0.59, p=$ 0.036).

Another sensitivity analysis was performed to explore the efficacy of EGFR-TKIs in current clinical trials with randomization and comparison. The difference in the LPFS was still statistically significant (HR: 0.63, $p=0.009$ ), which demonstrated that EGFR-TKIs could more effectively control local progression of cancer. Although the ORR did not favor EGFR-TKIs (OR: 4.81, $p=0.054)$, the ORRs in the EGFR-TKIs treatment group were clearly higher than those in the control group in all three clinical trials that reported the ORR (72.9 vs $24.2 \%, 54.1$ vs 47.1 $\%, 95.7$ vs $54.8 \%$ ). Therefore, the negative result in the ORR possibly originates from a lack of robustness in a few studies and the choice of random effects model due to high heterogeneity. The prolonged LPFS benefit did not translate into a benefit in the OS (HR: 0.97, $p=0.768$ ), and further well-designed $\mathrm{RCT}(\mathrm{s})$ with larger sample sizes are needed to investigate the effect of EGFR-TKIs in terms of an overall survival advantage.

Thus far, EGFR mutation status has been thought to be strongly associated with the response to EGFR-TKI therapy in patients with extra-cranial NSCLC $[38,39]$, but this correlation in patients with $\mathrm{BM}$ requires close scrutiny because the mutation status of primary and metastatic lesions may be different. The authors of a recent meta-analysis [15] observed therapeutic effects with an ORR of 85.0 vs 45.1 $\%$ and a disease control rate of 94.6 vs $71.3 \%$ for the EGFR mutation and unselected groups, respectively. In addition, individuals with EGFR mutations also demonstrated a therapeutic advantage in terms of median PFS and OS. This pooled analysis was based entirely on single-arm studies, and thus due to a lack of comparison, it could not be evaluated for statistical significance. In our meta-analysis, the pooled efficacy indicators in the subgroup with or without EGFR mutations could not be provided owing to the limited number of studies. However, the results of the evaluations of the efficacy of EGFR-TKI therapy were contradictory in only 2 subgroup analyses of 11 eligible studies [31,33]. Additional work is still required to clarify the impact of EGFR mutation status on the therapeutic benefit of EGFR-TKIs among patients with BM from NSCLC.

Some limitations were encountered and noted in the present pooled analysis. First, our metaanalysis was based on published studies; hence, any potential publication bias could not be eliminated. Second, we included five retrospective studies, which might have led to additional bias from the lack of randomization and the reference to historical data. Although a sensitivity analysis was performed by the inclusion of only 5 RCTs to control for the bias, a reduced study number may have restricted the reliability of the analysis. Third, the therapeutic effects of different EGFR-TKI agents could not be distinguished and compared on account of the number and background of the enrolled studies; nevertheless, it was recognized that the advantages of gefitinib, erlotinib and the new generation of EGFR-TKIs were different. Finally, high heterogeneity existed when we conducted the analysis of the ORR and OS. If possible, meta-analysis of individual patient data should be preferred.

\section{CONCLUSION}

It is evident from the present pooled analysis that EGFR-TKls has a therapeutic advantage over chemotherapy or radiotherapy for patients with BM from NSCLC; this conclusion is based on the elevation of the ORR and the improvement in OS and LPFS. Furthermore, large RCTs are required in order to determine the efficacy benefit and the influence of EGFR mutation status in clinical practice.

\section{DECLARATIONS}

\section{Conflict of Interest}

No conflict of interest associated with this work.

\section{Contribution of Authors}

The authors declare that this work was done by the authors named in this article and all liabilities pertaining to claims relating to the content of this article will be borne by them.

\section{Open Access}

This is an Open Access article that uses a funding model which does not charge readers or their institutions for access and distributed under the terms of the Creative Commons Attribution License (http://creativecommons.org/licenses/by/ 4.0) and the Budapest Open Access Initiative (http://www.budapestopenaccessinitiative.org/rea d), which permit unrestricted use, distribution, and reproduction in any medium, provided the original work is properly credited.

\section{REFERENCES}

Trop J Pharm Res, November 2017; 16(11): 2770 
1. Ferlay J, Parkin $D$, Shin $H$, Forman $D$, Mathers $C$, Parkin D, Bray F. GLOBOCAN 2002; 24(8): 1-4.

2. Reade CA, Ganti AK. EGFR targeted therapy in nonsmall cell lung cancer: potential role of cetuximab 2009; 3(default): 215-224.

3. Mamon HJ, Yeap BY, Jänne PA, Reblando J, Shrager S, Jaklitsch MT, Mentzer S, Lukanich JM, Sugarbaker DJ, Baldini EH. High risk of brain metastases in surgically staged IIIA non-small-cell lung cancer patients treated with surgery, chemotherapy, and radiation. J Clin Oncol 2005; 23(7): 1530-1537.

4. Barnholtz-Sloan JS, Sloan AE, Davis FG, Vigneau FD, Lai $P$, Sawaya RE. Incidence proportions of brain metastases in patients diagnosed (1973 to 2001) in the Metropolitan Detroit Cancer Surveillance System. J Clin Oncol 2004; 22(14): 2865-2872.

5. Nussbaum ES, Djalilian HR, Cho KH, Hall WA. Brain metastases: Histology, multiplicity, surgery, and survival. Cancer 1996; 78(8): 1781-1784.

6. Eichler AF, Chung E, Kodack DP, Loeffler JS, Fukumura $D$, Jain $R K$. The biology of brain metastases-translation to new therapies. Nat Rev Clin Oncol 2011; 8(6): 344345.

7. Broniscer A, Panetta JC, O'Shaughnessy M, Fraga C, Bai $F$, Krasin MJ, Gajjar A, Stewart CF. Plasma and cerebrospinal fluid pharmacokinetics of erlotinib and its active metabolite OSI-420. Clin Cancer Res 2007; 13(5): 1511-1513.

8. Zhao J, Chen M, Zhong W, Zhang L, Li L, Xiao Y, Nie L, Hu P, Wang M. Cerebrospinal fluid concentrations of gefitinib in patients with lung adenocarcinoma. Clin Lung Cancer 2013; 14(2): 188-193.

9. Miyata H, Sasaki T, Kuwahara K, Serikawa M, Chayama $K$. The effects of ZD1839 (Iressa), a highly selective EGFR tyrosine kinase inhibitor, as a radiosensitiser in bile duct carcinoma cell lines. Int J Oncol 2006; 28(4): 915-921.

10. Colquhoun AJ, Mchugh LA, Tulchinsky E, Kriajevska M, Mellon JK. Combination treatment with ionising radiation and gefitinib ('Iressa', ZD1839), an epidermal growth factor receptor (EGFR) inhibitor, significantly inhibits bladder cancer cell growth in vitro and in vivo. J Radiat Res 2007; 48(5): 351-360.

11. Ceresoli GL, Cappuzzo F, Gregorc V, Bartolini S, Crinò L, Villa $E$. Gefitinib in patients with brain metastases from non-small-cell lung cancer: a prospective trial. Ann Oncol 2004; 15(7): 1042-1045.

12. Park SJ, Kim HT, Lee DH, Kim KP, Kim SW, Suh C, Lee JS. Efficacy of epidermal growth factor receptor tyrosine kinase inhibitors for brain metastasis in non-small cell lung cancer patients harboring either exon 19 or 21 mutation. Lung Cancer 2012; 77(3): 556-558.

13. Lai CSL, Boshoff C, Falzon M, Lee SM. Complete response to erlotinib treatment in brain metastases from recurrent NSCLC. Thorax 2006; 61(1): 91-94.

14. Porta R, Sáncheztorres JM, Pazares L, Massutí B, Reguart N, Mayo C, Lianes P, Queralt C, Guillem V, Salinas $P$. Brain metastases from lung cancer responding to erlotinib: the importance of EGFR mutation. Euro Respir J 2011; 37(3): 624-627.

15. Yun $F, X u X$, Xie C. EGFR-TKI therapy for patients with brain metastases from non-small-cell lung cancer: a pooled analysis of published data. Onco \& Ther 2014; 2014(default): 2075-2084.

16. Luo S, Chen L, Chen X, Xie X. Evaluation on efficacy and safety of tyrosine kinase inhibitors plus radiotherapy in NSCLC patients with brain metastases. Oncotarget 2015; 6(18): 16725-16734.

17. Tao J, Min W, Li Y, Yue Z, Wu C, Zhou C. Radiotherapy plus EGFR TKIs in non-small cell lung cancer patients with brain metastases: an update meta-analysis. Cancer Med 2016(6): 1055-1065.

18. Lin CH, Hsu KH, Chang SN, Tsou HK, Sheehan J, Sheu $M L$, Pan HC. Increased survival with the combination of stereotactic radiosurgery and gefitinib for non-small cell lung cancer brain metastasis patients: a nationwide study in Taiwan. Radiation Oncol 2015; 10(1): 127-129.

19. Parmar MK, Torri V, Stewart L. Extracting summary statistics to perform meta-analyses of the published literature for survival endpoints. Statistics in Medicine 1998; 17(24): 2815- 2834.

20. Organization. WH. Declaration of Helsinki. Br Med J 1996; 313(7070): 1448-1449.

21. Higgins JP, Thompson SG, Deeks JJ, Altman DG. Measuring inconsistency in meta-analyses. Bri Med $J$ 2003; 327(7414): 557-560.

22. Dersimonian R, Nan L. Meta-analysis in clinical trials is. Controlled Clinical Trials 1986; 7(3): 177-188.

23. Woolf $B$. On estimating the relation between blood group and disease. Ann Human Genetics 1955; 19(4): 251 254.

24. Schnee S, Enoch $M$, Noriega-Crespo A, Sayers J, Terebey S, Caselli P, Foster J, Goodman A, Kauffmann $J$, Padgett $D$. Bias in meta-analysis detected by a simple, graphical test. Bmj 1997; 315(7109): 629-634.

25. Robins HI, O'Neill A, Mehta M, Grossman S. A phase 3 trial of whole brain radiation therapy and stereotactic radiosurgery alone versus WBRT \& SRS with temozolomide or erlotinib for non-small cell lung cancer and 1 to 3 brain metastases: Radiation Therapy Oncology Group 0320: in regard to Sperduto e. Int $J$ Radia Oncol Biol Phys 2013; 86(5): 809-810.

26. Schuler M, Wu YL, Hirsh V, O'Byrne K, Yamamoto $N$, Mok $T$, Popat S, Sequist LV, Massey $D$, Zazulina $V$. First-Line Afatinib versus Chemotherapy in Patients with Non-Small Cell Lung Cancer and Common Epidermal Growth Factor Receptor Gene Mutations and Brain Metastases. J Thorac Oncol 2016; 11(3): 380-390.

27. Cai Y, Wang JY, Liu H. Clinical observation of whole brain radiotherapy concomitant with targeted therapy for brain metastasis in non-small cell lung cancer patients with chemotherapy failure. Asian Pac J Cancer Prev 2013; 14(10): 5699-5703.

28. Lee SM, Lewanski CR, Counsell N, Ottensmeier C, Bates A, Patel N, Wadsworth C, Ngai Y, Hackshaw A, Faivrefinn C. Randomized trial of erlotinib plus whole-

Trop J Pharm Res, November 2017; 16(11): 2771 
brain radiotherapy for NSCLC patients with multiple brain metastases. J National Cancer Institute 2014; 106(7): 766-776.

29. Wang F, Ning F, LiU C, Hao Y, Li LM, Yu Z, Chen S, Li B. Comparison of Gefitinib Versus VMP in the Combination with Radiotherapy for Multiple Brain Metastases from Non-small Cell Lung Cancer. Cell Biochem Biophys 2015; 71(2): 1261-1265.

30. Zhuang H, Yuan Z, Wang J, Zhao L, Pang Q, Ping W. Phase II study of whole brain radiotherapy with or without erlotinib in patients with multiple brain metastases from lung adenocarcinoma. Drug Design Development \& Therapy 2013; 2013(default): 11791186.

31. Hsiao SH, Lin HC, Chou YT, Lin SE, Kuo CC, Yu MC, Chung CL. Impact of epidermal growth factor receptor mutations on intracranial treatment response and survival after brain metastases in lung adenocarcinoma patients. Lung Cancer 2013; 81(3): 455-458.

32. Fan $Y$, Huang Z, Fang L, Lulu M, Lin N, Gong L, Yu H, Yang $H$, Mao W. Chemotherapy and EGFR tyrosine kinase inhibitors for treatment of brain metastases from non-small-cell lung cancer: survival analysis in 210 patients. Onco Targets Ther 2013; 6(default): 17891803.

33. Pesce GA, Klingbiel D, Ribi K, Zouhair A, Moos RV, Schlaeppi M, Caspar CB, Fischer N, Anchisi S, Peters S. Outcome, quality of life and cognitive function of patients with brain metastases from non-small cell lung cancer treated with whole brain radiotherapy combined with gefitinib or temozolomide. A randomised phase II trial of the Swiss Group for Clinical Can. Euro Jo Cancer 2012; 48(3): 377-384.
34. Fu H, Zhang XL, Xiao Y, Liu XJ, Long C, Hu YD. [Evaluation of gefitinib plus radiotherapy in non-smallcell lung cancer patients with brain metastases]. Zhonghua Yi Xue Za Zhi 2012; 92(8): 524-527.

35. Togashi Y, Masago K, Masuda S, Mizuno T, Fukudo M, Ikemi $Y$, Sakamori $Y$, Nagai $H$, Kim YH, Katsura $T$. Cerebrospinal fluid concentration of gefitinib and erlotinib in patients with non-small cell lung cancer. Cancer Chemother Pharmacol 2012; 70(3): 399-405.

36. Zhuang $H$, Wang J, Zhao L, Yuan $Z$, Wang $P$. The theoretical foundation and research progress for WBRT combined with erlotinib for the treatment of multiple brain metastases in patients with lung adenocarcinoma. Int J Cancer 2013; 133(10): 2277-2283.

37. Welsh JW, Komaki R, Amini A, Munsell MF, Unger W, Allen PK, Chang JY, Wefel JS, Mcgovern SL, Garland LL. Phase II trial of erlotinib plus concurrent whole-brain radiation therapy for patients with brain metastases from non-small-cell lung cancer. J Clin Oncol 2013; 31(7): 895-902.

38. Lynch TJ, Bell DW, Sordella R, Gurubhagavatula $S$, Okimoto RA, Brannigan BW, Harris PL, Haserlat SM, Supko JG, Haluska FG. Activating mutations in the epidermal growth factor receptor underlying responsiveness of non-small-cell lung cancer to gefitinib. New England J Med 2004; 350(350): 21292139.

39. Paez JG, Jänne PA, Lee JC, Tracy S, Greulich H, Gabriel $S$, Herman P, Kaye FJ, Lindeman N, Boggon TJ. EGFR Mutations in Lung Cancer: Correlation with Clinical Response to Gefitinib Therapy 2004; 32(8): 1-5. 